DOI: $10.2507 / 28$ th.daaam.proceedings. 015

\title{
MEASURING OF FRICTION FACTOR OF CUTTING ENVIRONMENT
}

\author{
Marian Králik, Michal Bachratý, Marcela Pokusová \& Numan M. Durakbasa
}
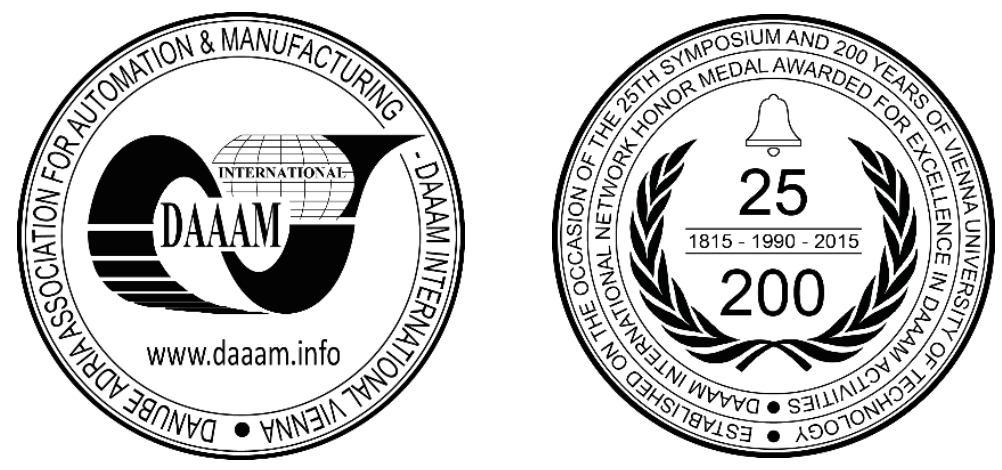

This Publication has to be referred as: Kralik, M[arian]; Bachraty, M[ichal]; Pokusova, M[arcela] \& Durakbasa, N[uman] (2017). Measuring of Friction Factor of Cutting Environment, Proceedings of the 28th DAAAM International Symposium, pp.0118-0123, B. Katalinic (Ed.), Published by DAAAM International, ISBN 978-3-902734-11-2, ISSN 1726-9679, Vienna, Austria

DOI: $10.2507 / 28$ th.daaam.proceedings.015

\begin{abstract}
At metals machining the cutting environment has a significant impact on the quality of the workpiece surface, a tool life and energy consumption. The paper deals with the results of research focusing on monitoring the friction properties of the most widely used cutting fluids. Cutting fluids appear to be an important means of increasing the productivity of technological processes, and require a complex knowledge of problems in the field of tribology, the theory of machining and chemical-physical processes. For this purpose the design of a tribometer and the methodology for evaluating the measured values is described. The measurement results contained in the table can be assumed to functionality and reliability of the proposed tribological device.

The experimental part of the research forms the basis for further research into the use of cutting fluids in the machining of components. It will analyse the impact of cutting fluids on the quality of the surfaces of work-pieces and the energy consumption during machining.
\end{abstract}

Keywords: machining; cutting environment; cutting fluid; sliding friction; friction force; surface roughness; tool life

\section{Introduction}

The importance of cutting environment for metals machining continues to grow and has a significant impact on improving the quality of the surface of the workpiece, tool life and reduce energy consumption [1 - 3]. Cutting fluids appear to be an important means of increasing the productivity of technological processes, and require a complex knowledge of problems in the field of tribology, the theory of machining and chemical-physical processes [4 - 6]. Lubricating effect of cutting environment in recent years appears to be the dominant effect, which significantly influences the economics of the cutting process [7]. As a criterion for evaluation of these properties is chosen factor of sliding friction, whose value can be determined experimentally on the equipment for simulation of the process for the two contact surfaces. The values of friction factor depend mainly on the particular pair of contacting surfaces, the material properties and the surface roughness of the bodies between the frictions occurs $[8,9]$. 


\section{Description the experimental equipment for monitoring of sliding friction factor}

Relatively many authors deal with the design and construction of tribometers to monitor the parameters of the cutting area [10 - 13]. Most authors characterize the requirements for their construction as follows: obtaining the characteristic traces of wear scar on the test sample, which is most important with regard to the analysis of friction properties. The test sample is usually always pressed onto the surface of the rotating ring mechanism that its kinematics, shape and the flow of cutting fluid is closest to a given cutting operation of machining [14-17]. Lubricating effect of cutting medium can be accurately entered using the resulting wear scar traces of the sample. Simple design, easy and quick replacement of cutting fluids and testing samples, minimizing the volume of tested cutting fluids, easy to adjust the contact force, the minimum eccentricity of the cylindrical surface of the ring etc. are other important requirements that should fulfill design and requirements for maintenance $[16,17]$. Test equipment, which was developed at the workplace of authors, is based on measurements of lubricating properties of cutting medium and the relationship between the load vector and velocity vector of motion. Tribotester was designed so that the axes of rotation of the two cylindrical surfaces of the friction are skew. The projection of these axes is 90 degrees. The projection of these axes is 90 degrees (Fig. 1).
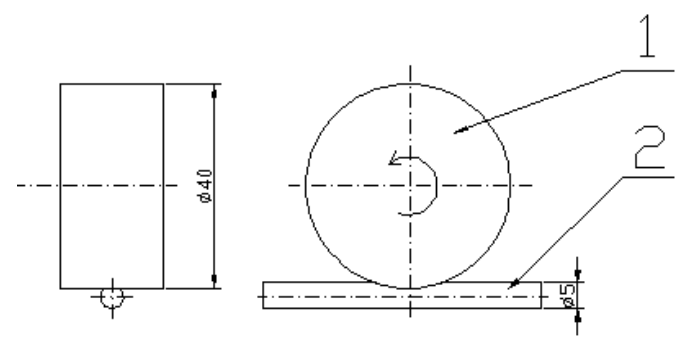

Fig. 1. Schematic representation of tribometer (1 - dynamometer 2 - test sample)

The ring makes a rotating movement around its own axis and lying in a skew position is pressed against the sample by means of a lever mechanism, fixed to the ring by gravity (Fig. 2). As an evaluation criterion was chosen off pressure contact between the frictions surfaces on which the continuous lubricating film, that prevents their direct contact adversely wear of test sample.

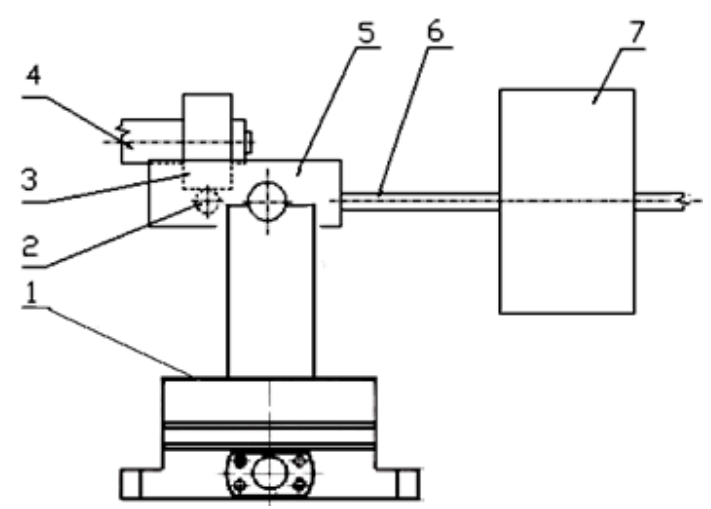

Fig. 2. Schematic representation of tribometer

(1 - dynamometer 2 - test sample, 3 - rotating ring, 4 - arbor work, 5 - container rocker, 6 - rocker arm, 7 - moving weight).

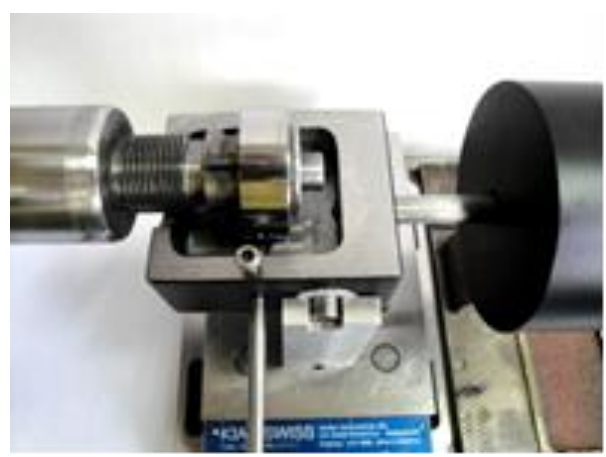

Fig. 3. Look at the fixing of tribometer in the spindle and longitudinal support of the lathe SV 18RD 
The ring of $40 \mathrm{~mm}$ diameter using a collet set on said driving thorns. This is clamped via cone M50 in the spindle lathe SV 18RD and insured against moving in the axial direction with a screw. The test sample is firmly clamped in a rocker and pushed against the rotating ring pinch. Tribometer cradle is rotatable mounted on the holder fixed on the dynamometer, which is bolted to the longitudinal traction support of the lathe (Fig. 3). An important element of tribometer is the elimination eccentricity, which, together with the inertia of the rocker arm may draw additional dynamic load of the system and thereby influence the value of the frictional power. The elimination of this negative phenomenon can be achieved by high surface quality with the final grinding and polishing the ring, which is clamped in the spindle lathe directly on a lathe.

\subsection{Test conditions of experiments}

The principal factors that influence the progress and results of the measurements on the laboratory tribotester are: pinch ring test sample, wear conditions, cutting environment, measuring devices, equipment and instruments. Pressure ring was made from the steel STN 19865 with respect to your specific requirements and function. The steel was hardened and tempered to $64 \mathrm{HRC}$ with the following parameters:

$\begin{array}{ll}\text { Inner grip diameter: } & d=20 \mathrm{~mm} \\ \text { Outside diameter: } & D=40 \mathrm{~mm} \\ \text { Width: } & w=22 \mathrm{~mm}\end{array}$$$
w=22 \mathrm{~mm}
$$

The roughness of the pressure ring was checked in transverse profile curve and the criterion of completion of surface preparation was the value of the arithmetical mean deviation $R a \leq 0.07$ microns.

Test of the sample - a cylindrical steel rod diameter $d=5 \mathrm{~mm}$, was made from the material STN 12050.1 and cut into in length of $l=100 \mathrm{~mm}$.

\subsection{Methodology of experimental measurements}

In the first phase of the experiment, we have created a track wear - the intersection of two cylindrical surfaces based on kinematic pairs - hardened abrasive ring and the sample, where was used as the loading force of $F_{n}=300 N$. The path length of abrasion was determined by measurement of expansion of the abrasive surface samples, depending on the path length of the ring in the sample. The size of abrasive surface was determined microscopically on the SmartScope MVP 200 (Fig. 4).

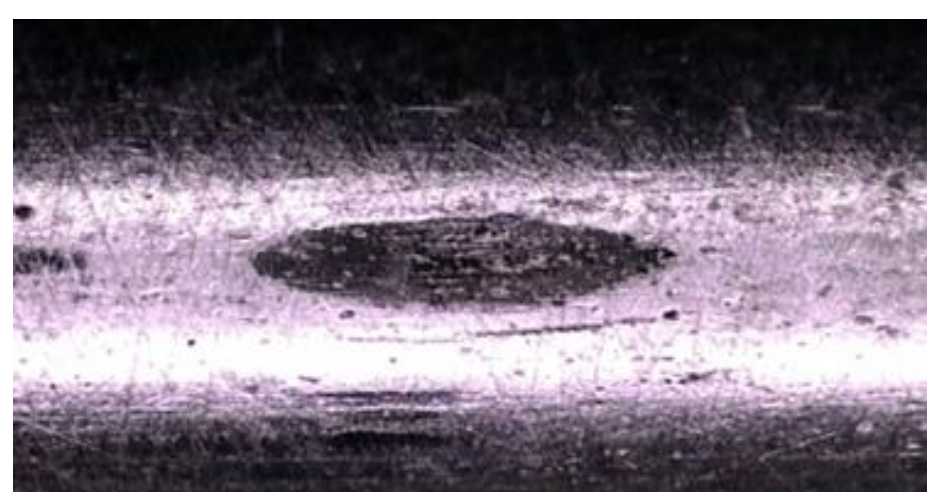

Fig. 4. Abrasive area on the sample surface

Measuring conditions:

- cutting environment: CF 1-26

- revolution per minute of the spindle $n=200 \mathrm{r} / \mathrm{min}$

- burdensome (normal) force of: $F_{n}=300 \mathrm{~N}$

- material of the ring: STN 19856

- material of the sample: STN 12050.1

In the second stage of the experiment was reduced the frictional force at such a value as not to up edge formation. Normal force was reduced from the value $F_{n}=300 \mathrm{~N}$ to $F_{n}=100 \mathrm{~N}$. Reducing forces was simultaneously reduced contact pressure, thus producing the secure lubrication film. Lubrication cutting medium from various manufacturers has been examined on this film (RP 1-26).

Size component friction force was captured by the three - component dynamometer KISTLER the type 9257. The bases of the dynamometer are sensors in the bridge connection placed in each sensing axis, which measures changes the electrical potential in relation to the energy burdening of the piezo crystal.

Normal forces are adjusted by means of adjustable weights, and were used calibrated weights $100 \mathrm{~N}$ and $300 \mathrm{~N}$ for the calibration. 
By means of measured values of the friction force $F_{t}$ and the known normal force $F_{n}=100 \mathrm{~N}$ is then possible to determine the factor of friction for each cutting environment. Degree of lubricity cutting medium was the size the factor of friction. It can be expressed by the formula:

$$
f=\frac{F_{t}}{F_{n}}
$$

$F_{t}-$ the shear frictional force on $(\mathrm{N})$

$F_{n}$ - the normal force between bodies (eg. body weight) (N)

\subsection{Statistical analysis and evaluation of the obtained results}

The result of measurement of the frictional force $F_{t}$ is an estimate of the actual value of the measured quantity (this corresponds on the dynamometer for component of force $F_{y}$ in the kinematic system of the machine tool); what for $i-t h$ measurement can be expressed by equation:

$$
\overline{F_{t_{i}}}=\frac{1}{n} \sum_{i=1}^{n} F_{t_{i}}
$$

Where $n$ is the number of the repeated measurements.

The evaluation of the standard uncertainty with the method $A$ is based on the statistical analysis of measured data. We assume that the measured values are obtained by the independent direct measurements under the same measurement conditions. Standard measurement uncertainty is evaluated by an estimation method $A$, which is expressed relations (2) and it is equal to the standard deviation the arithmetic average.

$$
u_{A}\left(F_{t_{i}}\right)=\sqrt{\frac{1}{n(n-1)} \sum_{i=1}^{n}\left(F_{t_{i}}-\overline{F_{t_{l}}}\right)^{2}}
$$

Measurement uncertainties are evaluated by the method $B$. They are linked on well-known and identifiable quantified sources, which are mainly linked to the measuring means. In measuring the friction force $F_{t}$ has been used the measuring device with constant measurement uncertainty at various subscale of the measuring instrument. The standard uncertainty of measurement, as assessed by using of the method $B$, is determined from the relationship:

$$
u_{B}\left(z_{i}\right)=\frac{z_{i \max }}{k}
$$

Where $k$ is the value which is a matter for the approximation of the normal distribution.

Consequently, it is possible to express the combined the measurement uncertainty with relations:

$$
u_{c}\left(F_{t_{i}}\right)=\sqrt{u_{A}^{2}\left(F_{t_{i}}\right)+u_{B}^{2}\left(z_{i}\right)}
$$

The standard measurement uncertainties overlap the actual measured value with only a small probability (around $66 \%$ ). A larger number of expected values are covered by the expanded uncertainty, which is obtained by using the factor $k$.

$$
U=k \cdot u_{c}\left(F_{t_{i}}\right)
$$

Examples of full record the results of measuring the friction force $F_{t}$ is as follows

$$
F_{t_{i}}=\left(\bar{F}_{t_{i}} \pm U\right) \quad[N]
$$

Statistical evaluation of the results of measurement of $F_{t}$ and the results of the friction factor are given in Table 1, and the graphical presentation of dependence between the estimated values of the frictional force $F_{t}$ and the used cutting fluids can be seen in Fig. 5. 


\begin{tabular}{|c|c|c|c|c|c|c|c|}
\hline Num. & $\operatorname{Max} \mathbf{Y}[\mathbf{N}]$ & $\operatorname{Min} \mathbf{Y}[\mathbf{N}]$ & $\begin{array}{c}\text { Average } \mathbf{Y} \\
{[\mathbf{N}]}\end{array}$ & $\mathbf{U A}\left(\mathbf{F}_{\mathbf{t}}\right)[\mathbf{N}]$ & $\mathbf{U B}\left(\mathbf{F}_{\mathbf{t}}\right)[\mathbf{N}]$ & $\mathbf{U C}\left(\mathbf{F}_{\mathbf{t}}\right)[\mathbf{N}]$ & f \\
\hline 1 & $-6,012202$ & $-54,824664$ & $-29,048982$ & 6,310236 & 1,154700538 & 6,415014553 & 0,29049 \\
\hline 2 & $-11,342898$ & $-76,356503$ & $-33,76166$ & 7,003226 & 1,154700538 & 7,097781889 & 0,337617 \\
\hline 3 & $-4,235303$ & $-64,440825$ & $-28,539748$ & 7,6109 & 1,154700538 & 7,697995333 & 0,285397 \\
\hline 4 & $-13,119797$ & $-71,130328$ & $-37,598341$ & 9,407398 & 1,154700538 & 9,477999286 & 0,375983 \\
\hline 5 & $-17,823354$ & $-65,695107$ & $-41,412462$ & 6,541256 & 1,154700538 & 6,642391391 & 0,414125 \\
\hline 6 & $-14,583126$ & $-81,896248$ & $-45,305565$ & 8,989203 & 1,154700538 & 9,063062612 & 0,453056 \\
\hline 7 & $-3,921732$ & $-72,07104$ & $-41,632422$ & 12,597702 & 1,154700538 & 12,65051102 & 0,416324 \\
\hline 8 & $-26,916896$ & $-83,882194$ & $-49,809314$ & 8,3088 & 1,154700538 & 8,3886525 & 0,498093 \\
\hline 9 & 1,408964 & $-54,615617$ & $-26,853241$ & 8,315234 & 1,154700538 & 8,395025301 & 0,268532 \\
\hline 10 & $-1,204122$ & $-42,804464$ & $-21,963729$ & 5,607136 & 1,154700538 & 5,724797591 & 0,219637 \\
\hline 11 & 1,095394 & $-49,493967$ & $-22,689293$ & 6,877333 & 1,154700538 & 6,973596097 & 0,226893 \\
\hline 12 & $-11,133852$ & $-55,242758$ & $-34,973398$ & 5,813571 & 1,154700538 & 5,927135995 & 0,349734 \\
\hline 13 & $-11,342898$ & $-48,239685$ & $-29,382542$ & 5,025589 & 1,154700538 & 5,156537417 & 0,293825 \\
\hline 14 & $-20,43644$ & $-60,677979$ & $-40,795055$ & 6,004212 & 1,154700538 & 6,11423708 & 0,407951 \\
\hline 15 & $-7,266483$ & $-44,999457$ & $-26,740433$ & 5,236117 & 1,154700538 & 5,361926386 & 0,267404 \\
\hline 16 & $-4,130779$ & $-40,818518$ & $-23,866435$ & 4,914895 & 1,154700538 & 5,048715301 & 0,238664 \\
\hline 17 & 7,575849 & $-73,325321$ & $-43,846772$ & 11,865426 & 1,154700538 & 11,92147925 & 0,438468 \\
\hline 18 & $-10,715758$ & $-55,242758$ & $-33,760549$ & 5,892287 & 1,154700538 & 6,004363365 & 0,337605 \\
\hline 19 & $-8,416241$ & $-54,824664$ & $-32,024988$ & 7,371016 & 1,154700538 & 7,460912156 & 0,32025 \\
\hline 20 & $-0,681505$ & $-40,713994$ & $-23,164837$ & 4,816616 & 1,154700538 & 4,953092269 & 0,231648 \\
\hline 21 & $-7,520765$ & $-66,158436$ & $-31,237965$ & 8,222961 & 1,154700538 & 8,303639018 & 0,31238 \\
\hline 22 & $-3,921732$ & $-61,409644$ & $-27,695846$ & 6,617638 & 1,154700538 & 6,717623541 & 0,276958 \\
\hline 23 & $-14,583126$ & $\begin{array}{l}-51,68896 \\
\end{array}$ & $-32,737425$ & 5,879984 & 1,154700538 & 5,992290478 & 0,327374 \\
\hline 24 & $-20,750011$ & $-74,684127$ & $-47,903293$ & 7,646252 & 1,154700538 & 7,732949177 & 0,479033 \\
\hline 25 & $-8,520765$ & $-67,158436$ & $-31,879182$ & 8,222961 & 1,154700538 & 8,303639018 & 0,318792 \\
\hline 26 & $-24,094762$ & $-66,217724$ & $-46,450293$ & 6,285635 & 1,154700538 & 6,390816903 & 0,464503 \\
\hline
\end{tabular}

Table 1. Statistical evaluation of the results of measurement of $F_{t}$ and the results of the friction factor

\section{Number of cutting fluid}

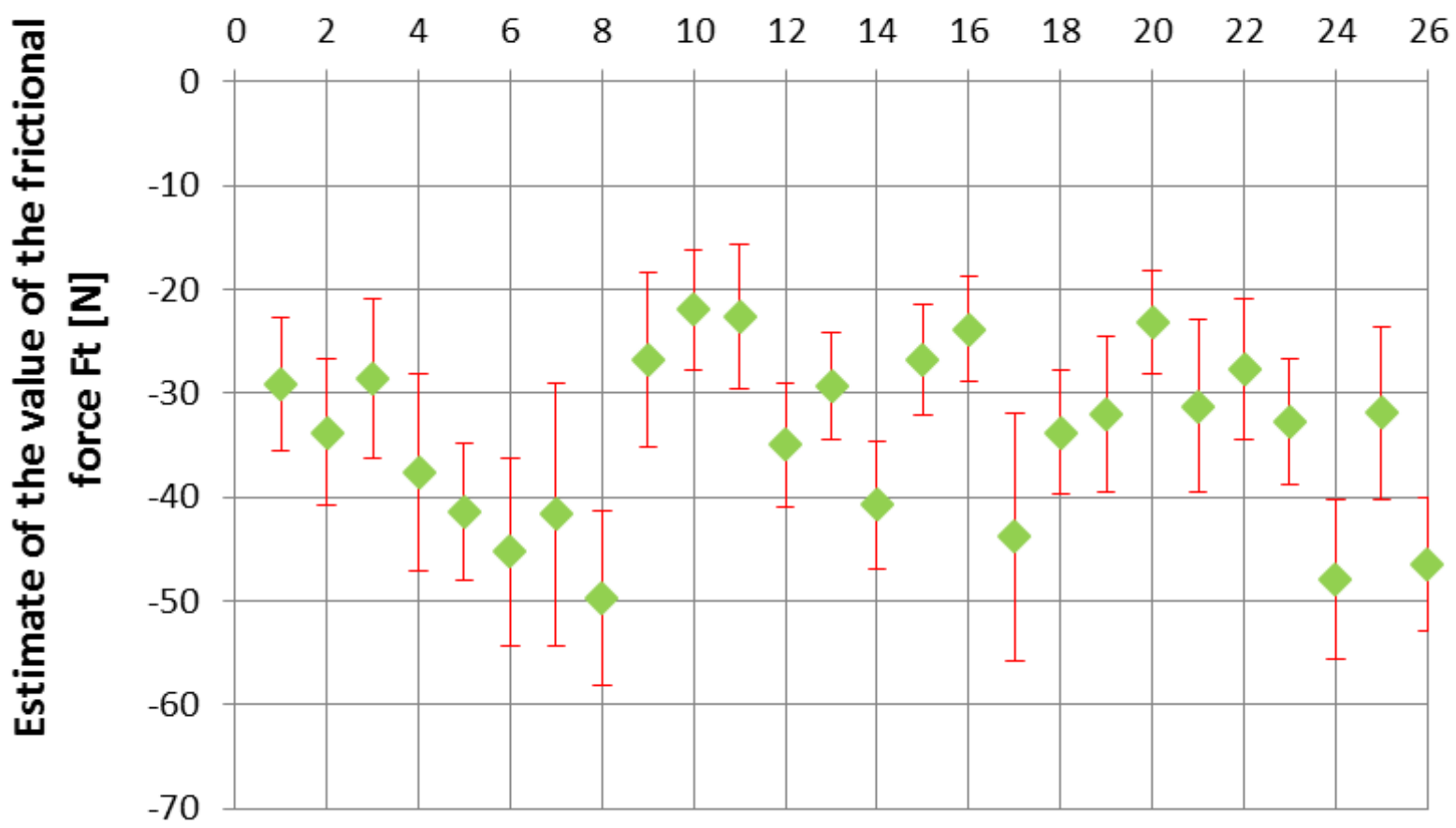

Fig. 5. Dependence of estimated value of the frictional force $F_{t}$ and the use of cutting fluid 


\section{Conclusion}

The achieved results can be considered criterial, therefore, an indicator of lubricating properties of the cutting fluids. Thus, they are an indicator of lubricating properties of the cutting fluids. It is therefore appropriate to take the further measurements of the available cutting fluids under the same measuring conditions. The results can create a database of indicators of their suitability for the machining process.

Tests of cutting fluids will be performed in the machining process itself - turning of the external rotating surfaces.

The methodology of influence of the cutting fluids on the electric energy consumption will be determined for selected machining parameters. The cutting environment also influences the quality of the surface layer, the residual stress in the surface layers, the stability of the machining process, etc. These areas will be the subject of further research, the aim of which will be selecting the optimal cutting fluids so as to achieve the selected criteria relating to the quality of the workpieces and the energy consumption during machining.

\section{Acknowledgments}

The performed research was the content of the project the Ministry of Education, Science, Research and Sport of the Slovak Republic KEGA 1/1056/12 "The introduction of progressive educational methods for manufacturing systems to car production" that also provided the background for our paper and the bilateral project APVV SK-AT-2015-0023 "Improvement of production quality in selected application".

\section{References}

[1] Vasilko, K. (1997). Znižovanie energetickej a ekologickej náročnosti procesu obrábania. Zborník z medzinárodnej konferencie. Perspektívy a horizonty SR. Trenčianske Teplice. 22. - 23. október 1997. pp. 175 - 177.

[2] Kocman, K. (2011). Technologické procesy obrábění CERM, 2011, Brno, ISBN 978-80-7204-722-2

[3] Prokop, J. \& Kocman, K. (2005). Technologie obrábění, CERM, 2005, Brno, ISBN 80-214-3068-0.

[4] Neslušan, M. \& Čilliková, M. Teória obrábania (2007). Žilina : Žilinská univerzita, 2007, ISBN 978-80-8070-7903.

[5] Camposeco-Negrete, C. (2013) Optimization of cutting parameters for minimizing energy consumption in turning of AISI 6061 T6 using Taguchi methodology and ANOVA. Journal of Cleaner Production 53, (2013.), p.195-203, ISSN: 0959-6526.

[6] Ghani, J.A. \& Choudhury, I.A. \& Hassan, H.H. (2004) Application of Taguchi method in the optimization of end milling parameters. Journal of Materials Processing Technology 145, (2004.), p. 84-92, ISSN: 0924-0136.

[7] Fratila \& Domnita \& Caizar \& Cristian. (2011). Application of Taguchi method to selection of optimal lubrication and cutting conditions in face milling of AlMg3. Journal of Cleaner Production 19, (2011.), p. 640-645, ISSN: 09596526.

[8] Kara, S. \& Li, W. (2011) Unit process energy consumption models for material removal processes. CIRP Annals e Manufacturing Technology 60, (2011.), p. 37-40, ISSN: 0007-8506.

[9] Muminovic, A. \& Repcic, N. \& Colic, M. (2014) Thermo Elasto Hydrodynamic Lubrication Model of Mixed Friction. 24th DAAAM International Symposium on Intelligent Manufacturing and Automation. In Procedia Engineering 69, (2014.), p. 49 - 56, ISSN: $1877-7058$

[10] Behrendt, T., Zein, A., Min, S. (2012). Development of an energy consumption monitoring procedure for machine tools. CIRP Annals - Manufacturing Technology 61, (2012.), p.43-46, ISSN: 0007-8506.

[11] Kuhrke, B. \& Schrems, S. \& Eisele, C. \& Abele, E. (2010). Methodology to Assess the Energy Consumption of Cutting Machine Tools. Conference Proceedings LCE - 2010, 17th CIRP International Conference on Life Cycle Engineering (Hefei, China), (2010.) p. 76-82, ISBN: 978-75-6500-186-4.

[12] Verl, A. \& Abele, E. \& Heisel, U. \& Dietmair, A. \& Eberspächer, P. \& Rahäuser, R. \& Schrems, S. \& Braun, S. (2011). Modular Modeling of Energy Consumption for Monitoring and Control. In: Glocalized Solutions for Sustainability in Manufacturing, (Hesselbach, J., et al.) p. 341-346, Springer-Verlag, Berlin, Heidelberg, Germany, Print ISBN 978-3-642-19691-1.

[13] He, Yan \& Liu, Bo \& Zhang, Xiaodong \& Gao, Huai \& Liu, Xuehui. (2012) A modeling method of task-oriented energy consumption for machining manufacturing system. Journal of Cleaner Production 23 (2012.), 167-174, ISSN: 0959-6526.

[14] Li, W. \& Kara, S. (2011). An Empirical Model for Predicting Energy Consumption of Manufacturing Processes: A Case of Turning Process, In: Proceedings of the Institution of Mechanical Engineers, Part B: Journal of Engineering Manufacture 255, (2011.), p. 1636-1646, ISSN: 09544054.

[15] Quintana, G. \& Ciurana, J. \& Ribatallada, J. (2011). Modeling power consumption in ball-end milling operations. Materials and Manufacturing Processes 26, (2011.), p. 746-756, Online ISSN: 1532-2475.

[16] Eberspächer, P. \& Verl, A. (2013). Realizing energy reduction of machine tools through a control integrated consumption graph-based optimization method. Forty Sixth CIRP Conference on Manufacturing Systems 2013 , In. Procedia CIRP 7 (2013.), p. 640 - 645, ISSN: 2212-8271.

[17] Bi, Z.M. \& Wang, L. (2012). Optimization of machining processes from the perspective of energy consumption: A case study. In. Journal of Manufacturing Systems 31, (2012.), p. 420-428, ISSN: 0278-6125. 